\title{
An experimental and numerical investigation of the thermal and non-thermal efficiency for counterflow heat exchanger
}

\author{
Marek Borowski ${ }^{1}$, Michat Karch ${ }^{1}$, Stawosz Kleszcz ${ }^{1,2,}{ }^{*}$, Pawet Sala ${ }^{1}$, and Grzegorz Waryan ${ }^{2}$ \\ ${ }^{1}$ AGH University of Science and Technology, Faculty of Energy and Fuels, Kraków, Poland \\ ${ }^{2}$ Frapol Sp. z o.o., Kraków, Poland
}

\begin{abstract}
Heating, ventilation and air conditioning systems are responsible for a significant part of total energy consumption in operated buildings. To decrease energy consumption in the near future, all buildings will have mechanical ventilation with heat recovery. In such system heat exchanger is the essential part of the system responsible for effective energy recovery from exhaust air. However, the main disadvantage of this type of unit is heat exchanger freezing during winter. To solve this issue in the present research a special air distribution system in the heat exchanger was developed. The periodic-flow unit under investigation consists of a standard counter flow heat exchanger and a set of opposing air dampers used to appropriately cyclically modify the direction of air flow through the heat exchanger. Proposed in the studies modification eliminate the negative aspect of unit freezing during the winter season as well as ensure proper air humidity. It has been found that the thermal efficiency for the heat exchanger is $83.5 \%$. However, some internal leakage in manufactured unit occurs which artificially raised this parameter. The estimated value from the energy balance of was lower about $80.3 \%$. The value of the heat exchanger efficiency falls within the range $80.3-82.8 \%$.
\end{abstract}

\section{Introduction}

Energy consumption (electrical, heat or oil) in facilities is becoming very important in the all parts of the World[1]. As a result, a significant number of new buildings are created with almost zero energy demand (ZEB) [2]. Owing to energy-saving design as well as renewable energy systems (photovoltaic, solar collector) there is a real chance to execute that requirement in passive houses. A large amount of primary energy is waste during heating, cooling and ventilation and this is the reason why implementation of heat recovery systems becomes crucial. Besides energy savings, heat recovery ventilation system provides proper air recirculation, fresh air and better fully controlled microclimate [3].

Mechanical gravity systems are based on highefficiency air-to-air heat exchangers [4], which ability to heat recovering from the extract air from the room a system whose advantages cannot be overestimated. Research studies [5] shown that by applying such a recovery system the total annual energy consumption can be reduced at least by $20 \%$ in cold climates [5]. However, this required a new solution to maintain the desired indoor air quality all the time [6-8].

At present, there are many different types of heat recovery installations that exchange energy from exhaust to fresh air and vice versa [9-11]. Most of them can be divided into two main groups: ordinary exchangers recovering sensible heat, and enthalpic exchangers which recover latent heat as well as sensible heat [12]. The heat recovery efficiency of available units varies between $60 \%-95 \%$. In most of the solutions the fresh air flowing through the heat exchanger - depends on the season - is cooled or heated by the exhaust air and further flows into the rooms. In the case of counterflow exchangers, the streams flowing through do not mix.

The heat exchange takes place through thin layers of individual plates, which separate two streams of air, warm and cold. There are different types of air flow systems, including counter, cross or parallel flow [13-14]. In the case of counterflow heat exchangers, the typical efficiency of sensible heat exchange is between $50 \%-80 \%$ [15], and this solution has also a low-pressure drop as well as surfaces are relatively easy to clean [16]. They are an excellent way to get a very efficient heat recovery. High heat transfer coefficients, in combination with the counter flow, allow reaching temperatures very near to the temperature of extracted air [17]. However, a primary disadvantage of this type of heat exchangers is their freezing during winter season [18]. Currently, a lot of experimental and numerical research studies $[20,21]$ are underway to avoid this phenomenon without using nonprimary energy (electrical heaters) for example a special guide vane [19]. 
In this work, the plate heat exchanger - one of the most popular heat exchangers is analysed. It is constructed of alternatingly arranged thin plates forming air flow channels (Fig. 3). An analysed heat exchanger consists of flat plates separated by the plates with fins. The thermal and non-thermal unit efficiency has been evaluated under laboratory controlled environmental conditions. The method of testing devices is performed according to the 13141-7 standard. The tests were carried out to determine the parameters of the novel ventilation unit equipped with a standard counterflow heat exchanger. Experimental results were compared with numerical simulation and validated model allow to optimise heat exchanger construction in the future.

\section{Experimental methodology}

The experimental measurement was performed to determinate the temperature, humidity, sensible and latent efficiency of the air handling unit and to compare selected results with numerical ones. The measurement procedure has been done under conditions presented in PN EN 13141-7 standard (Table 1).

Table 1. Temperature conditions.

\begin{tabular}{cccc}
\hline \multicolumn{2}{c}{ Extract air } & \multicolumn{2}{c}{ Outdoor air } \\
\hline $\mathrm{T}_{11}$ & $\mathrm{~T}_{\mathrm{w} 11}$ & $\mathrm{~T}_{21}$ & $\mathrm{~T}_{\mathrm{w} 21}$ \\
$\left({ }^{\circ} \mathrm{C}\right)$ & $\left({ }^{\circ} \mathrm{C}\right)$ & $\left({ }^{\circ} \mathrm{C}\right)$ & $\left({ }^{\circ} \mathrm{C}\right)$ \\
\hline 20 & 12 & 7 & - \\
\hline
\end{tabular}

The $\mathrm{T}_{\mathrm{w}}$ in Table1 is the wet bulb temperature of the air and indexes presented in Table 1. are as follows (see also Figure 1.):
22 - the fresh air,
11 - the room air,
21 - the ambient air,
12 - the waste air.

The test was carried in the laboratory of the heat exchanger manufacturer. The measured parameters such as temperature $\left(T_{21}, T_{22}, T_{11}, T_{12}\right)$, pressure $\left(p_{21}, p_{22}, p_{11}\right.$, $\left.p_{12}\right)$ and humidity $\left(\varphi_{21}, \varphi_{22}, \varphi_{11}, \varphi_{12}\right)$ were done by according to PNEN 308 standard. The air flow rates $\left(\mathrm{V}_{21}\right.$, $\mathrm{V}_{22}, \mathrm{~V}_{11}, \mathrm{~V}_{12}$ ) were measured by using the Venturi tube.

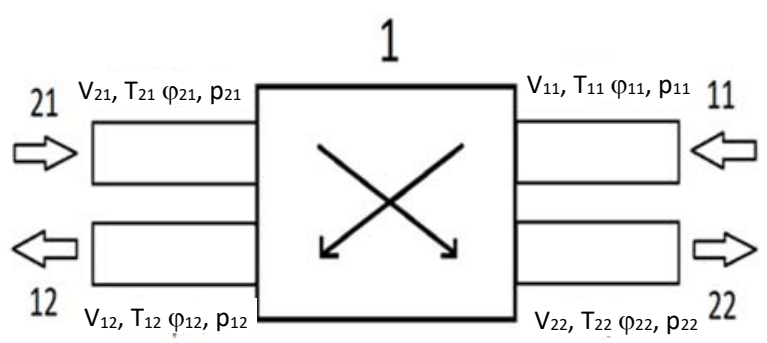

Fig. 1. Diagram of the test section.

From the test chamber which simulated outdoor conditions, the air was drawn by channel 21 , while from the warm chamber which simulated the conditions inside the ventilated rooms, the air was drawn by channel 11 . Respectively the channel 22 contains the fresh air while channel 12, waste air. All acquired thermal and flow parameters were sampled with a temporal resolution equal to $1 \mathrm{~s}$ and recorded for a period equal to $600 \mathrm{~s}$. The temperature and humidity conditions of the outside and extract air were fully stabilized for the period of the $1800 \mathrm{~s}$. The temperature efficiency of a heat exchanger was calculated as the ratio of the heat flux recovered by the heat exchanger transferred to or extracted from the supply air in reference to the total heating power required to heat the outside air to indoor air temperatures. The evaluated results are corrected by multiplying the ratio of the mass flow of supply air and extract air.

Efficiency ratio on the supply air side:

$$
\eta_{t, s u}=\frac{T_{22}-T_{21}}{T_{11}-T_{21}} \cdot \frac{q_{m 22}}{q_{m 11}}
$$

Humidity ratio on the supply air side:

$$
\eta_{x, s u}=\frac{x_{22}-x_{21}}{x_{11}-x_{21}} \cdot \frac{q_{m 22}}{q_{m 11}}
$$

where: $\mathrm{T}$ it the temperature of air $\left({ }^{\circ} \mathrm{C}\right), \mathrm{x}$ - the absolute moisture content $(\mathrm{g} / \mathrm{kg}), \mathrm{q}_{\mathrm{m}}$ is the mass flow of air $(\mathrm{kg} / \mathrm{h})$, and index: for balanced units, the flow ratio of $q_{m 22}$ and $q_{m 11}$ should be up to $3 \%$.

\section{Numerical analysis of heat exchanger}

In this work, a three-dimensional model of the heatexchanger module has been created in order to analyse the fluid flow and the heat transfer phenomena. The sketch of the analysed geometry and the key components are presented in Figs. 2-4. Due to a large number of repeatable elements, the shape of the exchanger has been simplified. The original heat exchanger has 78 pairs of flat plates elements, alternating with wavy plates. The wavy part of the element consists of 316 small flat elements, oblique walls with a thickness of $0.048 \mathrm{~mm}$.

In order to perform numerical simulation, the computational domain has been simplified to one diagonal wall and the proportional surface of the horizontal wall. The height of the model consists of seven layers with an adiabatic upper and lower boundary condition. It has been analysed with test calculation that this number is sufficient in order to obtain a number of layers' independent results.

The numerical results are analysed for the middle layer. The mesh SingleZone mesh was generated on the entire domain except for the wavy wall, where the MultiZone method was used. After several analyses, final mesh with 552469 elements was used as a mesh provided mesh-independent results. 


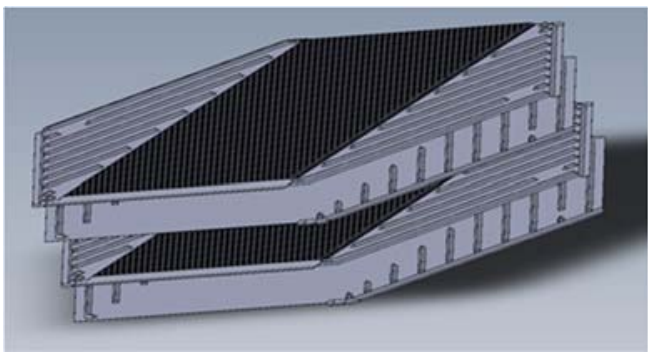

Fig. 2. The sketch of the analysed geometry.

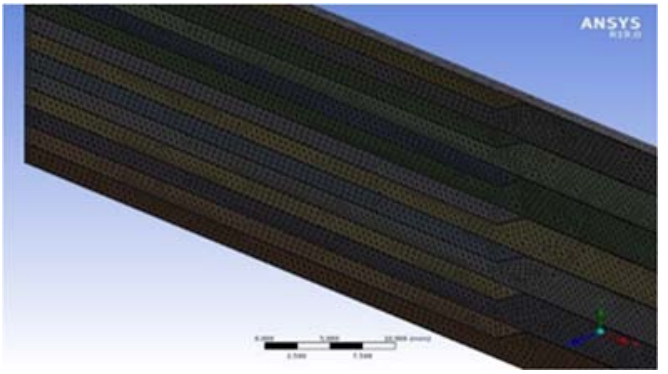

Fig. 3. Mesh created on the object.

In this research studies, it assumed that temperature is a passive scalar and have no influence on the air flow. The analysed flow is assumed to be steady state, Newtonian with negligible viscosity dissipation. The time-averaged governing equations for continuity, momentum and energy in tensor notation, are as follows:

$$
\begin{gathered}
\frac{\partial \bar{U}_{i}}{\partial x_{i}}=0 \\
\bar{U}_{j} \frac{\partial \bar{U}_{i}}{\partial x_{j}}=-\frac{1}{\rho} \frac{\partial \bar{P}}{\partial x_{i}}+v \frac{\partial^{2} \bar{U}_{i}}{\partial x_{j}^{2}}-\frac{\partial}{\partial x_{j}}\left(\overline{u_{i} u_{j}}\right) \\
\bar{U}_{j} \frac{\partial \bar{T}}{\partial x_{j}}=\kappa \frac{\partial^{2} \bar{T}}{\partial x_{j}^{2}}-\frac{\partial}{\partial x_{j}}\left(\overline{u_{j} \theta}\right)
\end{gathered}
$$

where $x_{i}, x_{j}$ are the Cartesian coordinates of the system, $\bar{U}, \bar{P}, \bar{T}$ are the mean velocity, dynamic pressure and temperature respectively; $v, \kappa$ are fluid viscosity and thermal diffusivity. In order to model turbulent flow the realizable $k-\varepsilon$ model which is a modification of the standard $k-\varepsilon$ model was used. Model is a semi-empirical 2-equation eddy viscosity model, which is based on the Boussinesq hypothesis - Reynolds stresses can be expressed in terms of mean velocity gradients and that the turbulent eddy viscosity is related to the turbulent kinetic energy and the dissipation rate of turbulent kinetic energy. The $k-\varepsilon$ turbulence models incorporate, on average, the influence of turbulent eddies (Reynolds stresses) through turbulent viscosity, which is related to the fluid rate of strain. The Realizable $k-\varepsilon$ is used because this model contains an improved formulation for the turbulent viscosity and performed much better than other turbulence models for this type of geometry. As a numerical solver Fluent ver. 19 was used. The fluid and solid properties used un analysis are presented in Table 2.

Table 2. Fluid and solid properties.

\begin{tabular}{ccccc}
\hline $\begin{array}{c}\text { Material } \\
\text { name }\end{array}$ & $\begin{array}{c}\text { Specific } \\
\text { heat } \\
(\mathrm{J} / \mathrm{kgK})\end{array}$ & Density & $\begin{array}{c}\text { Viscosity/ } \\
\text { Emissivity } \\
\left(\mathrm{kg} / \mathrm{m}^{3}\right)\end{array}$ & $\begin{array}{c}\text { Thermal } \\
\text { conductivity } \\
(\mathrm{kg} / \mathrm{ms}) /(-)\end{array}$ \\
\hline Air & 1006.4 & 1.225 & $1.7894 \mathrm{e}-05$ & 0.0242 \\
Plate & 1300 & 1040 & - & 0.15 \\
\hline
\end{tabular}

\section{Result and discussion}

The analysis was carried out based on the equipment manufactured on a massive scale. In the catalogue sheet for the analysed exchanger, the heat efficiency was around $82.3 \%$. Figures $4-7$ present results of measurements for the fluid flow, temperature and humidity made on each side of the heat exchanger during the test. Figure 4 shows that the temperature was stable over the whole measurement and almost the same as in Table1.

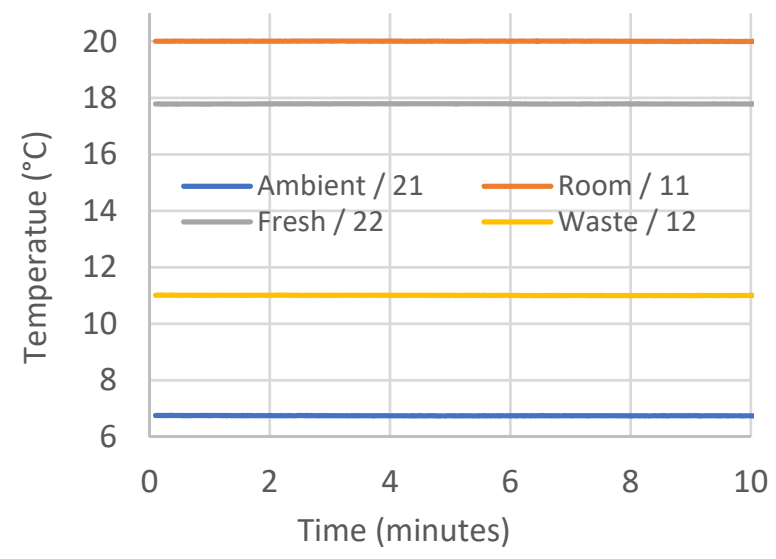

Fig. 4. The air temperature through the heat exchanger.

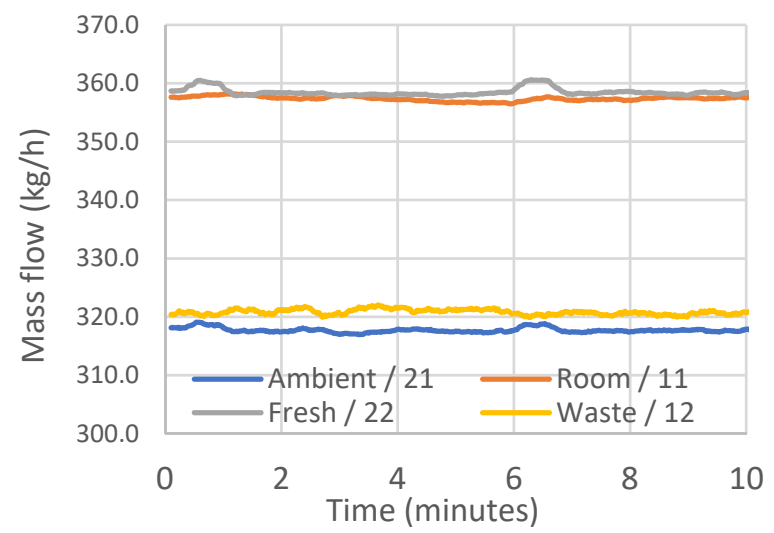

Fig. 5. The air flow through the heat exchanger.

In Figure 6 the ratio of $q_{\mathrm{m} 22}$ and $q_{\mathrm{m} 11}$ is equal to 0.995 . However, the $\mathrm{q}_{\mathrm{m} 21} \neq \mathrm{q}_{\mathrm{m} 22}$ and the $\mathrm{q}_{\mathrm{m} 11} \neq \mathrm{q}_{\mathrm{m} 12}$ what suggests the internal leakage in the manufactured unit equal to $\mathrm{q}_{\mathrm{ml}}=40.8\left(\mathrm{~m}^{3} / \mathrm{h}\right)$. 


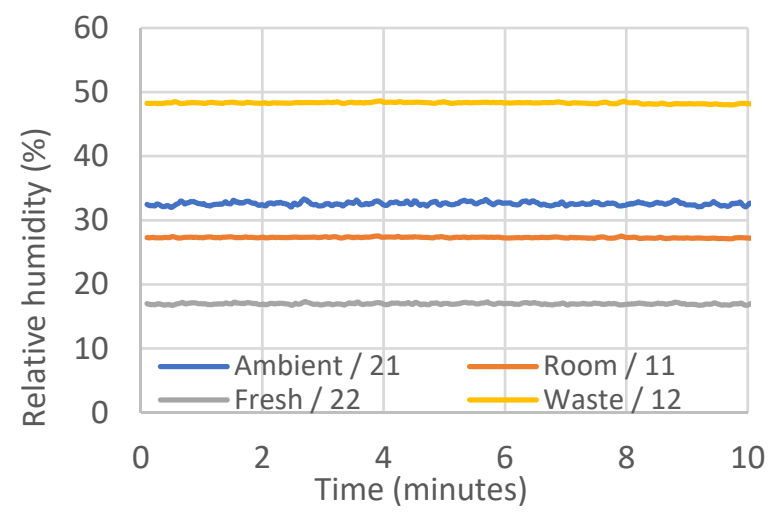

Fig. 6. The air relative humidity.

As can be seen in Figure 7 there is a rise of water content in the fresh air relative to ambient air. The water may come from the extract air due to leakage.

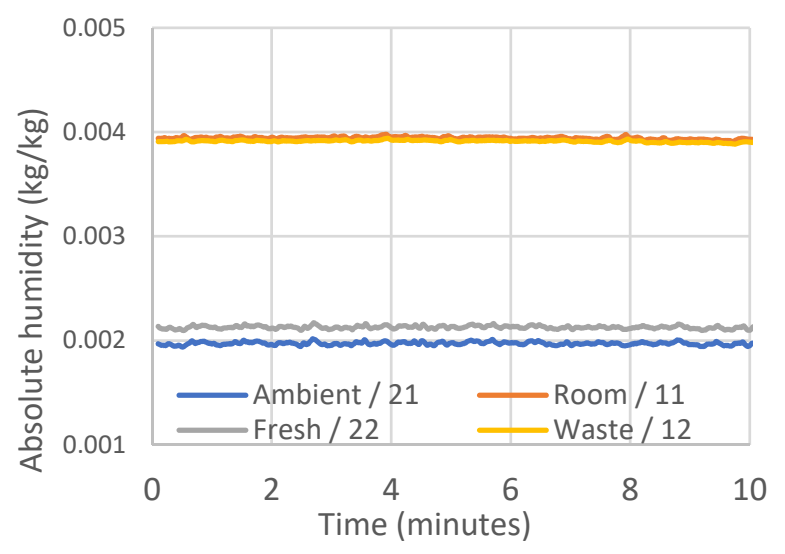

Fig. 7. Water content in air flow.

There are two possible internal leakages. The first one from room air to the fresh air and second from waste air to ambient air. According to Table 3, the leakage from waste to ambient air is more likely due to occurring pressure on each side of the heat exchanger unit.

Table 3. Measure pressure on each side of the heat exchanger.

\begin{tabular}{cccc}
\hline $\mathrm{p}_{11}$ & $\mathrm{p}_{12}$ & $\mathrm{p}_{21}$ & $\mathrm{p}_{22}$ \\
$(\mathrm{~Pa})$ & $(\mathrm{Pa})$ & $(\mathrm{Pa})$ & $(\mathrm{Pa})$ \\
\hline-28.3 & 26 & -31.2 & 19.1 \\
\hline
\end{tabular}

The efficiency of the unit oscillates around $83.5 \%$ and this value is a bit larger than the values provided by the manufacturer.

Table 4. Energy balance from averaged parameters.

\begin{tabular}{ccccc}
\hline $\begin{array}{c}\text { Index } \\
(-)\end{array}$ & $\begin{array}{c}\mathrm{q}_{\mathrm{m}} \\
(\mathrm{kg} / \mathrm{h})\end{array}$ & $\begin{array}{c}\mathrm{T} \\
\left({ }^{\circ}\right)\end{array}$ & $\begin{array}{c}\mathrm{q}_{\mathrm{cp}} \\
\left(\mathrm{kg} / \mathrm{m}^{3}\right)\end{array}$ & $\begin{array}{c}\mathrm{Q} \\
(\mathrm{W})\end{array}$ \\
\hline 21 & 317.8 & 6.7 & 1.005 & 594.42 \\
\hline 22 & 358.6 & 17.8 & 1.005 & 1781.94 \\
\hline 11 & 357.4 & 20 & 1.005 & 1995.48 \\
\hline 12 & 321 & 11 & 1.005 & 985.74 \\
\hline
\end{tabular}

When internal leakage occurs, the efficiency for the heat exchanger should be recalculated. In this case, an energy balance was calculated using the average air parameters presented in Table 4.

The disproportion of heat flux:

$$
\theta=1-\frac{Q_{22}-Q_{21}}{Q_{11}-Q_{12}}=1-\frac{1187.52}{1009.75}=17.6 \%
$$

Assuming that $\mathrm{q}_{\mathrm{m} 21}$ should be equal $\mathrm{q}_{\mathrm{m} 22}$ as well as $\mathrm{q}_{\mathrm{m} 11}$ and $\mathrm{q}_{\mathrm{m} 12}$ and the leakage is from $\mathrm{q}_{\mathrm{m} 12}$ to $\mathrm{q}_{\mathrm{m} 21}$ the corrected energy balance can be provided:

$$
\begin{gathered}
\mathrm{Q}_{12}{ }^{*}=\mathrm{q}_{\mathrm{m} 11} \cdot \mathrm{T}_{12} \cdot \mathrm{q}_{\mathrm{cp} 12}=897.97 \mathrm{~W} \\
\mathrm{~T}_{21}{ }^{*}=\frac{\mathrm{Q}_{22}-\mathrm{Q}_{11}+\mathrm{Q}_{12}}{\mathrm{q}_{\mathrm{m} 21} \cdot \mathrm{q}_{\mathrm{cp} 21}} \cdot 3.6=8.83^{\circ} \mathrm{C}
\end{gathered}
$$

Table 5. Energy balance from recalculated parameters.

\begin{tabular}{ccccc}
\hline $\begin{array}{c}\text { Index } \\
(-)\end{array}$ & $\begin{array}{c}\mathrm{q}_{\mathrm{m}} \\
(\mathrm{kg} / \mathrm{h})\end{array}$ & $\begin{array}{c}\mathrm{T} \\
\left({ }^{\circ} \mathrm{C}\right)\end{array}$ & $\begin{array}{c}\mathrm{q}_{\mathrm{cp}} \\
\left(\mathrm{kg} / \mathrm{m}^{3}\right)\end{array}$ & $\begin{array}{c}\mathrm{Q} \\
(\mathrm{W})\end{array}$ \\
\hline $21^{*}$ & 358.6 & 8.83 & 1.005 & 883.96 \\
\hline 22 & 358.6 & 17.8 & 1.005 & 1781.94 \\
\hline 11 & 357.4 & 20 & 1.005 & 1995.48 \\
\hline $12^{*}$ & 357.4 & 11 & 1.005 & 897.97 \\
\hline
\end{tabular}

The disproportion of heat flux:

$$
\theta^{*}=1-\frac{Q_{22}-Q_{21}}{Q_{11}-Q_{12}}=1-\frac{897.98}{897.97}=0 \%
$$

The corrected efficiency has been calculated using equation (1):

$$
\eta_{\mathrm{t}, \mathrm{su}}{ }^{*}=\frac{\mathrm{T}_{22}-\mathrm{T}_{21}{ }^{*}}{\mathrm{~T}_{11}-\mathrm{T}_{21}{ }^{*}} \cdot \frac{\mathrm{q}_{\mathrm{m} 22}{ }^{*}}{\mathrm{q}_{\mathrm{m} 11}{ }^{*}}=80.3 \%
$$

Considering this fact, the ambient temperature of air should be:

$$
\begin{aligned}
& \mathrm{q}_{\mathrm{m} 21}{ }^{* *}=\mathrm{q}_{\mathrm{m} 21}+\mathrm{q}_{\mathrm{ml}}=358.6 \frac{\mathrm{kg}}{\mathrm{h}} \\
& \mathrm{T}_{21}{ }^{* *}=\frac{\mathrm{q}_{\mathrm{m} 21} \cdot \mathrm{T}_{21}+\mathrm{q}_{\mathrm{ml}} \cdot \mathrm{T}_{12}}{\mathrm{q}_{\mathrm{m} 21}+\mathrm{q}_{\mathrm{ml}}}=7.19^{\circ} \mathrm{C}
\end{aligned}
$$

The corrected efficiency obtained from recalculation using equation (1) is as follows:

$$
\eta_{\mathrm{t}, \mathrm{su}}{ }^{* *}=\frac{\mathrm{T}_{22}-\mathrm{T}_{21}{ }^{* *}}{\mathrm{~T}_{11}-\mathrm{T}_{21}{ }^{* *}} \cdot \frac{\mathrm{q}_{\mathrm{m} 22}{ }^{* *}}{\mathrm{q}_{\mathrm{m} 11}}=82.8 \%
$$

From the other hand results from numerical simulation provided similar results which are summarised in Table 6 . The efficiency obtained from the numerical investigation is equal:

$$
\eta_{\mathrm{t}, \mathrm{su}}=\frac{\mathrm{T}_{22}-\mathrm{T}_{21}}{\mathrm{~T}_{11}-\mathrm{T}_{21}} \cdot \frac{\mathrm{q}_{\mathrm{m} 22}}{\mathrm{q}_{\mathrm{m} 11}}=76.82 \%
$$

There was provided second calculation with resulted are present in Table 7 and the efficiency was equal: 


$$
\eta_{\mathrm{t}, \mathrm{su}}=\frac{\mathrm{T}_{22}-\mathrm{T}_{21}}{\mathrm{~T}_{11}-\mathrm{T}_{21}} \cdot \frac{\mathrm{q}_{\mathrm{m} 22}}{\mathrm{q}_{\mathrm{m} 11}}=87.96 \%
$$

\section{Conclusion}

The heat exchanger thermal efficiency obtained from the experimental measurement was $83.5 \%$. However, based on measurement some internal leakage was observed which artificially raised this parameter. From the energy balance of exchanger, the efficiency was equal to $80.3 \%$ but further calculation shown that there was not enough thermal energy from leakage to heat up the outdoor temperature to $\mathrm{T}_{21}{ }^{*}=8.83{ }^{\circ} \mathrm{C}$. It can be assumed that other physical phenomena such as heat convection through the steel layer raised the general efficiency of the unit. The value of the heat exchanger efficiency falls within the range 80.3 and $82.8 \%$. Numerical calculations showed that for disproportion flows and tight exchanger the efficiency should not exceed $76.82 \%$ and for recalculated parameters (Table 7) equal $87.96 \%$ in comparison to equation 11. It needs to be highlighted that simulation was made only for simplified exchanger and the energy balance was made for the whole unit. There was a lot of steel surface area to lose heat after the heat exchanger unit. To sum up, there is not a possibility to evaluate the precise efficiency of the unit where the leakage was observed. In the first step for the exact determination of efficiency unit, the maximum value of heat transfer should be tested. After that, the unit should be tested on tightness and then if all streams are equal the unit is ready for final efficiency test.

ACKNOWLEDGMENTS. The present work was partially supported by the Ministry of Science and Higher Education Republic of Poland, Contract No. 0039/DW/2018/02.

\section{References}

1. EU, Directive 2010/31/EU of the European Parliament and of the council of 19 May 2010 on the energy performance of buildings.

2. M. Kapsalaki, V. Leal, Recent progress on net zero energy buildings, Adv. Build. Energy, Res. 5 (2011)

3. L. Shao, SB. Riffat, G. Gan, Heat recovery with low pressure loss for natural ventilation, Energy Build., 28 (1998)

4. Y.P. Zhou, J.Y. Wu, R.Z Wang, Performance of energy recovery ventilator with various weather and temperature set points, Energy Build., 39 (2007)

5. M. Fehrm, W. Reiners, M. Ungemach, Exhaust air heat recovery in buildings, Int. Journal of Refrigeration, 25 (2002)

6. J. Szmyd, M. Branny, M. Karch, W. Wodziak, M. Jaszczur, R. Nowak, Experimental and numerical analysis of the air flow in T-shape channel flow, Arch. Mining Sci., 58 (2013)
7. M. Borowski,M. Jaszczur, D. Satoła, M. Karch, Air flow characteristics of a room with air vortex diffuser, MATEC Web of Conf. 240 (2018)

8. M. Jaszczur, L.M. Portela, Numerical data for reliability of LES for non-isothermal multiphase turbulent channel flow, ERCOFTAC 12 (2008)

9. M. Fehrm, W Reiners, M. Ungemach, Exhaust air heat recovery in buildings, Int. Journal of Refrigeration, 25 (2002)

10. M. A. El-Baky, M. M Mohamed, Heat pipe heat exchanger for heat recovery in air conditioning, App. Thermal Eng., 27 (2007)

11. E. Juodis, Extracted ventilation air heat recovery efficiency as a function of a building's thermal properties, Energy Build., 38 (2006)

12. J. Dieckmann, K.W. Roth, J. Brodrick, Air-to-air energy recovery heat exchangers, ASHRAE Journal, 45 (2003)

13. M. Jaszczur, M. Borowski, M. Karch, M. Branny, The study of the velocity field of the air flowing the swirl diffusers using PIV method, EPJ Web of Conf., 143 (2017)

14. ASHRAE, ASHRAE handbook of fundamentals American Society of heating, Atlanta, GA: Refr. and Air-Conditioning Eng (2005)

15. ASHRAE, ASHRAE handbook HVAC systems and equipment (2008)

16. R. Howell, H.J. Saver, W.J. Coad, Principles of heating ventilating and air conditioning, ASHRAE (1982)

17. B.R. Lamb, Plate heat exchangers - a low cost route to heat recovery, Journal of Heat Recovery Systems, 2 (1982)

18. M. Jaszczur, M. Borowski, D. Satoła, S. Kleszcz, M. Karch, Analysis of the temperature, humidity, and total efficiency of the air handling unit with a periodic counterflow heat exchanger, Thermal Science, 23 (2019)

19. M. Borowski, M. Jaszczur, D. Satoła, S. Kleszcz, M. Karch, An analysis of the innovative exhaust air energy recovery heat exchanger, MATEC Web of Conf., 240 (2018)

20. M. Jaszczur, Numerical analysis of a fully developed non-isothermal particle-laden turbulent channel flow, Archives of Mechanics, 8 (2011)

21. M. Jaszczur, R. Nowak, J. Szmyd, M. Karch, W. Wodziak, An application of SPIV technique to experimental validation of the turbulence model for the air flow in the intersection of the mining face with the ventilation gallery, J. Phys. Conf. Ser., 318 (2011) 